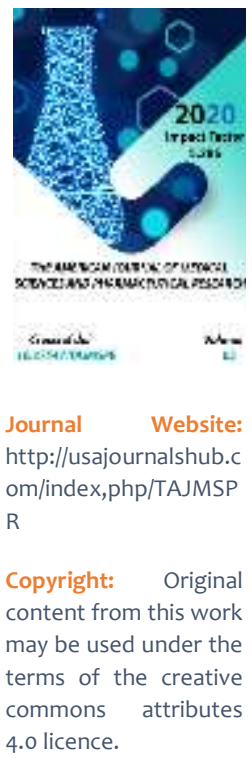

\section{Preoperative Preparation Of Elderly Patients With Concomitant Hypertension In The Practice Of Ophthalmic Surgery}

\author{
Mansur Muratovich Matlubov \\ Doctor Of Science, Head Of Chair Of Anesthesiology And Reanimatology, \\ Samarkand State Medical Institute, Uzbekistan \\ Jasur Tolibovich Yusupov \\ Assistant, Chair Of Anesthesiology And Reanimatology, Samarkand State Medical Institute, \\ Uzbekistan \\ Nigina Ulugbekovna Mukhamedieva \\ Chair Of Anesthesiology And Reanimatology, Samarkand State Medical Institute, Uzbekistan
}

\title{
ABSTRACT
}

Background: The relevance of the problem of arterial hypertension ( $\mathrm{AH}$ ) is determined by its high frequency in the population, the influence on the state of health, working capacity and longevity of the population. Persons of old and old age, as a rule, have a significant amount of risk factors for cardiovascular diseases, very often there are lesions of target organs and associated clinical conditions, therefore, the majority of painful AHs of these age-related categories belong to high and very high-risk groups.

Purpose of the research: To optimize the existing methods of managing elderly and senile patients with hypertension during cataract extraction, including preoperative assessment of patients' condition and preparation, intraoperative protection.

Materials and methods: Clinical observations cover 150 patients aged 60 to 89 years ( $74.7 \pm 0.5)$, who were required for surgical treatment for age-related cataracts in the department of ophthalmology at the Sam clinic. Depending on the method of anesthesiology, all patients were divided into 2 groups.

Results: All patients with hypertension on the background of an antihypertensive therapy have clinically achieved the target numbers for arterial pressure. . Arterial hypertension before surgery in patients of the II group testified to a pressurized reaction of the cardiovascular system (CCC) in response to psycho-emotional irritation and a short-term associated with it. After the operative period, indicators of the functional state of the CVS improved, however, tachycardia of the heart rate of 85.4 \pm 1.4 use of antihypertensive and pain-relieving drugs. In patients of the l-group, the SAD stabilized at $87.7 \pm 3.7 \mathrm{~mm} \mathrm{Hg}$, heart rate $66.2 \pm 3.4$ beats. in minutes at the l-stage already after premedication.

Conclusion. The results of the study suggest that conducting adequate antihypertensive therapy in combination with drugs that reduce mental and emotional stress in the preoperative period, exclusion of eye contact, psychoemotional stress through sedation and neuroleptanalgesia in waiting rooms 
allows to stabilized the clinical state of patients, clearly correlating with an improvement in hemodynamic parameters.

\section{KEYWORDS}

Cataract, hypertension, sedation, neuroleptanalgesia, central hemodynamics.

\section{INTRODUCTION}

The demographic situation in the world is characterized by an increase in life expectancy, and, accordingly, the number of older people in society. With increasing life expectancy, the number of chronic diseases, primarily cardiovascular diseases, increases $[1,2,10]$. Among the latter, the first place is occupied by arterial hypertension $[4,6,8]$. At the same time, there is a large number of elderly and senile patients who need to use surgical methods of treatment for a particular pathology of the surgical profile. And among them, a large proportion belongs to patients with concomitant arterial hypertension [9,13]. The presence of concomitant pathology increases the degree of operational and anesthetic risk $[2,3]$. Optimal control of elevated blood PRESSURE in the elderly is an urgent problem, since high blood pressure is the main risk factor for cardiovascular complications $[3,6,10]$. The variety of drugs used for the treatment of hypertension, the high incidence of complications in such patients, and the lack of development of methods to protect patients from operational stress in hypertension give the problem special significance. Another major problem of elderly and senile people is the loss of vision caused by the development of age-related cataracts. According to leading ophthalmologists, age-related cataracts affect almost all patients older than 70 years. In Russia, 180,000 cataract extraction operations are performed annually, which is $10 \%$ of the existing demand [5]. Patients of ophthalmic surgery departments who are admitted for surgical treatment for age-related cataracts are elderly and senile people who suffer from hypertension in $50-80 \%$ of cases. Uncompensated blood pressure during cataract extraction is the cause of serious intraand postoperative complications. It is known that psychoemotional stress on the eve and during the operation creates an additional load on the cardiovascular system and causes, as a rule, an increase in blood pressure [7,11,12,14]. The above allows us to classify elderly and senile patients with concomitant hypertension as patients at high risk of intra-and postoperative complications and require an individual approach to each specific clinical situation.

\section{MATERIALS AND METHODS}

The study included 150 patients (70 men and 80 women) aged 60 to 89 years $(74.7 \pm 0.5)$ who were treated in the department of ophthalmology of the 1st clinic of Samarkand state medical institute. All the patients we observed were preparing for cataract extraction surgery as planned. Depending on the method of anesthesia, all patients were divided into 2 groups. Group I patients were given afobazole $10 \mathrm{mg}$ at night and sibazone (benzodiazepine) $0.5 \%-0.15 \mathrm{mg} / \mathrm{kg}$ on the day 
of surgery, diphenhydramine ( $0.2 \mathrm{mg} / \mathrm{kg}$ ) and neuroleptanalgesia (NLA) droperidol $0.25 \%$ 0.25-0.5 mg / kg, fentanyl 0.005\%-0.005 mg/ kg, mydriacil $0.5 \%-15 \mathrm{ml}$ instilled $1-2$ drops in 30 minutes. Before the operation, patients were kept in waiting rooms until the effect of sedation was complete. It should be noted that patients of the I-main group refused to administer atropine due to the negative effect on the CVS. Patients of the II-control group $(n=72)$ underwent standard premedication on the operating table with atropine $0.1 \%-1.0 \mathrm{mg}$, diphenhydramine $1 \% \quad-0.2 \quad \mathrm{mg} / \mathrm{kg}, \quad \mathrm{NLA}$ (droperidol 0.25\%-0.5 mg/kg, fentanyl 0.005\% $0.005 \mathrm{mg} / \mathrm{kg}) .30$ minutes after premedication, group I patients were transferred to the operating room in a drowsy state. After treatment with antiseptics, the operating field was punctured with a retrobulbar space under local infiltration anesthesia in a horizontal position; in the absence of a vascular bundle puncture, a $2 \%$ lidocaine solution of $2-5 \mathrm{ml}$ was administered retrobulbar. Surgical intervention was started with the development of a complete motor block of the eyeball. Repeated doses of lidocaine were not required. The infusion program was based mainly on saline solutions.

All patients received regular antihypertensive, pulse-reducing, and vasodilating medication prior to surgery to correct existing cardiovascular disorders and hypertension. The drug doses were selected individually and did not exceed the recommended maximum daily doses. Patients of the main group (group 1) additionally received afobazole $10 \mathrm{mg} 2-3$ times a day.

According to the ASA classification by initial physical condition, all patients were classified as class II-III. All patients suffered from concomitant hypertension, and had complications of its flow: ischemic heart disease, angina II-III functional class according to Canadian classification -22 (28,2\%), myocardial infarction (MI) in anamnesis - 9 (11,5\%), 2 of them repeatedly; complex cardiac arrhythmias and conduction - 14 (17,9\%), chronic heart failure I-III degree NYHA - 12 $(15,4 \%)$. In all the studied patients, CCC disorders were of a combined nature.

In all patients, middle blood pressure (MBP) was calculated using the formula: (Systolic blood pressure $+2 *$ diastolic blood pressure)/3, heart rate(HR), blood oxygen saturation $(\mathrm{SpO} 2)$ were measured continuously throughout the operation and postoperative period using the MPR6-03-Triton monitor (Russia).

The study was performed at the following stages: stage 1-in 30 minutes. before the operation (initial values); stage 2-on the operating table; stage 3 - the most traumatic moment of the operation; stage 4-after the operation; stage 5 - the day after the operation.

We studied the complications and side effects directly or indirectly related to the anesthetic aid.

All numerical values obtained during the study were processed by the method of variation statistics using the Student's criterion.

\section{RESULTS}

The diagnosis of HD was made on the basis of anamnesis, complaints, clinical picture of the disease, risk factors, data from clinical, laboratory and instrumental methods of examination according to the recommendations of ESH/ESC (2013). According to the results of the analysis, $\mathrm{AH}$ was found in 78 patients had $\mathrm{AH}$, while the elderly (52\%), and in old age, $\mathrm{AH}$ was in 63 patients (42\%), while long-livers had 9 cases $(6 \%)$, also had $\mathrm{AH}$. 
When analyzing the ratio of first-time and reoperated patients, it was found that the vast majority of patients were operated on for the first time $(n=91)$, or re-operated $(n=59)$. At the same time, the latter had already undergone 12 and sometimes 3 ophthalmic surgeries by the time of cataract extraction. The vast majority of first-time patients were aged 60-75 years, and the cataract was accompanied by hypertension. When analyzing the nature of ophthalmic pathology, it was found that the main cause of cataract extraction was agerelated cataracts in $74 \%$ of cases, complicated cataracts (diabetic, traumatic, swollen cataracts) that occur with concomitant diseases of the visual organs, caused by General diseases of the body, trauma are less common and accounted for $26 \%$. In the majority of patients ( $n=149)$, an OMLENS intraocular lens was subsequently implanted to improve vision. In cases of cataract extraction with damage to the posterior capsule of the eye, such operations ended with the removal of only the cataract mass.

The overwhelming majority of patients $(n=78)$ had concomitant grade 2 hypertension, which accounted for $52 \%$ of the total number of patients $(n=150), 44$ patients had grade 1 hypertension (29.3\%), and only 28 patients had grade 3 hypertension (18.7\%). As a rule, these were patients with high and very high risk of hypertension. This category of patients often had lesions of target organs (82.6\%) and associated clinical conditions (68.7\%).

The frequency of risk factors and target organ damage in patients with age-related cataracts was as follows. Smoking as a risk factor was present in 39 patients (26\%), dyslipidemia $(\mathrm{OH}>4.9 \mathrm{mmol} / \mathrm{l})$ was present in $21(14 \%)$, obesity (BMI $\geq 30 \mathrm{~kg} / \mathrm{m} 2)$ or abdominal obesity (OK: $\geq 102 \mathrm{~cm}$ in men, $\geq 88 \mathrm{~cm}$ in women) - in 10 patients (6.7\%), fasting plasma glucose or impaired glucose tolerance $(5.6-6.9 \mathrm{mmol} / \mathrm{l})$ in 28 patients (18.7\%). Left ventricular hypertrophy according to electrocardiography was present in 122 patients (81.3\%), pulse pressure $\geq 60 \mathrm{mmHg}$. in 106 patients (70.7\%), proteinuria - in 32 patients (21.3\%).

All patients with hypertension on the background of the chosen antihypertensive therapy was clinically achieved the target blood pressure numbers. The effect of therapy was evaluated based on the results of multiple measurements of clinical blood pressure (using the method of N. S. Korotkov).

Baseline BP was determined as the average of 3 consecutive BP values recorded by the heart monitor immediately before surgery. Against the background of selected antihypertensive therapy in patients of group I and II treated with antihypertensive drugs, significantly low indicators of SBP, DBP, PBP, and MBP were revealed.

In the analysis of blood pressure monitoring data, a comparative analysis of hemodynamic parameters was performed at the stages of research in patients with hypertension, comparing with the comparison group, the indicators were considered during surgery (stages 2, 3) and postoperative period (stages $4,5)$ see table 1. 
The American Journal of Medical Sciences and Pharmaceutical Research (ISSN - 2689-1026)

Published: November 20, 2020 | Pages: 8-15

Table 1.

Comparative analysis of hemodynamic parameters at the stages of anesthesia.

\begin{tabular}{|c|c|c|c|c|c|c|}
\hline \multirow[b]{2}{*}{ 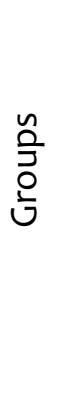 } & \multirow[t]{2}{*}{ Parameter } & \multicolumn{5}{|c|}{ Research stages } \\
\hline & & $\begin{array}{l}\text { Primary } \\
\text { data }\end{array}$ & $\begin{array}{l}\text { On the } \\
\text { operation } \\
\text { table }\end{array}$ & $\begin{array}{l}\text { The most } \\
\text { traumatic } \\
\text { moment of } \\
\text { the } \\
\text { operation }\end{array}$ & $\begin{array}{l}\text { One hour } \\
\text { after the } \\
\text { operation }\end{array}$ & $\begin{array}{c}\text { One day } \\
\text { after the operation }\end{array}$ \\
\hline \multirow{5}{*}{$\begin{array}{l}\frac{0}{7} \\
\frac{1}{0} \\
\frac{1}{1}\end{array}$} & SBP & $\begin{array}{l}128,2 \pm 3 \\
2\end{array}$ & $125,4 \pm 4,2$ & $124,8 \pm 5,2$ & $123,4 \pm 1,4^{*}$ & $128,8 \pm 3,4^{* *}$ \\
\hline & DBP & $71,7 \pm 1,8$ & $68,4 \pm 3,3$ & $69,3 \pm 3,1$ & $67,9 \pm 2,4 *$ & $73,2 \pm 1,8 * *$ \\
\hline & MBP & $\begin{array}{l}90,6 \pm 1 \\
8\end{array}$ & $87,7 \pm 3,7$ & $87,6 \pm 4,1$ & $87,2 \pm 1,9$ & $91,6 \pm 2,6$ \\
\hline & $\mathrm{HR}$ & $\begin{array}{l}69,2 \pm 2, \\
4\end{array}$ & $65,2 \pm 3,4$ & $65,8 \pm 3,2$ & $66,5 \pm 1,6$ & $70,1 \pm 2,4$ \\
\hline & $\mathrm{SpO}_{2}$ & $\begin{array}{l}98,1 \pm 0, \\
4\end{array}$ & $\begin{array}{ll} & 98,2 \pm \\
0,5 & \end{array}$ & $97,9 \pm 0,4$ & $98,0 \pm 0,7$ & $98,1 \pm 0,9$ \\
\hline \multirow{5}{*}{$\begin{array}{l}\stackrel{0}{7} \\
\frac{0}{00} \\
\text { ì }\end{array}$} & SBP & $\begin{array}{r}13 \\
0,1 \pm 2,9\end{array}$ & $\begin{array}{r}180,8 \\
\pm 4,4 * * * \Delta\end{array}$ & $\begin{array}{l}132,3 \pm 2,4 * \\
* \Delta\end{array}$ & $\begin{array}{l}135,4 \pm 1,9^{*} \\
\Delta\end{array}$ & $* * \Delta$ \\
\hline & DBP & $\begin{array}{r}71 \\
, 6 \pm 1,8\end{array}$ & $\begin{array}{r}100,0 \\
\pm 2,2 * * * \Delta\end{array}$ & $\begin{array}{l}82,4 \pm 3,6 * \\
* * \Delta\end{array}$ & $85,3 \pm 1,7 \Delta$ & $95,4 \pm 3,3 * * *$ \\
\hline & MBP & $\begin{array}{r}9 \\
1,3 \pm 2,1\end{array}$ & $\begin{array}{r}127,0 \\
\pm 3,2 * * * \Delta\end{array}$ & $\begin{array}{l}98,8 \pm 4,5^{*} \\
* * \Delta\end{array}$ & $\begin{array}{l}101,4 \pm 2,4^{*} \\
\Delta\end{array}$ & $\begin{array}{l}113,6 \pm 3,9 * \\
* * \Delta\end{array}$ \\
\hline & HR & $\begin{array}{r}6 \\
8,2 \pm 1,4\end{array}$ & $\begin{array}{r}88,4 \pm \\
2,7 * * * \Delta\end{array}$ & $\begin{array}{l}82,0 \pm 2,3 * \\
* * \Delta\end{array}$ & $71,4 \pm 3,1 * *$ & $78,4 \pm 3,2 * * *$ \\
\hline & $\mathrm{SpO}_{2}$ & $\begin{array}{r}9 \\
8,2 \pm 0,5\end{array}$ & $\begin{array}{ll} & 97,7 \pm \\
0,4 & \end{array}$ & $98,0 \pm 0,7$ & $98,1 \pm 0,7$ & $98,3 \pm 0,4$ \\
\hline
\end{tabular}

Comparative analysis of hemodynamic parameters at the stages of anesthesia. 
Note:*-p1-significance of differences in comparison with the initial values;

$\Delta$-p2-In comparison with the previous stage of the study;

Severe bleeding from the episcleral vessels and from the vessels of the iris during the operation, which required diathermocoagulation of the bleeding vessels and irrigation of the hyphema, was often observed in patients of group 2 (12.5\%). These complications were not observed in patients of the main group.

Table 2. presents data on the observed hemodynamic disorders in patients with concomitant arterial hypertension in the postoperative period.

Table 2.

Frequency of postoperative hemodynamic disorders in elderly patients with arterial hypertension

\begin{tabular}{|c|c|c|c|c|c|c|}
\hline \multirow{3}{*}{$\begin{array}{c}\text { Nature of hemodynamic } \\
\text { disorders } \\
\text { Excessive hypertensive }\end{array}$} & \multicolumn{4}{|c|}{ Group of patients } & \multirow{2}{*}{\multicolumn{2}{|c|}{$\begin{array}{l}\text { Total } \\
\mathrm{n}=150\end{array}$}} \\
\hline & \multicolumn{2}{|c|}{$1^{\text {st }}$ group $n=78$} & \multicolumn{2}{|c|}{$2^{\text {nd }}$ group $n=72$} & & \\
\hline & 7 & $9 \%$ & 29 & $40,3 \%$ & 36 & $24 \%$ \\
\hline $\begin{array}{c}\text { Excessive hypotensive } \\
\text { reactions }\end{array}$ & 1 & $1,3 \%$ & 5 & $6,9 \%$ & 6 & $6,0 \%$ \\
\hline $\begin{array}{l}\text { Heart rhythm and } \\
\text { conduction disorders }\end{array}$ & 6 & $7,7 \%$ & 18 & $25 \%$ & 24 & $16,0 \%$ \\
\hline $\begin{array}{c}\text { Impaired renal function } \\
\text { (postoperative decrease in } \\
\text { diuresis) }\end{array}$ & 3 & $3,8 \%$ & 10 & $13,9 \%$ & 13 & $8,7 \%$ \\
\hline $\begin{array}{l}\text { Postoperative myocardial } \\
\text { ischemia }\end{array}$ & - & - & 2 & $2,9 \%$ & 2 & $1,3 \%$ \\
\hline Acute myocardial infarction & - & - & 1 & $1,4 \%$ & 1 & $0,7 \%$ \\
\hline Transient ischemic attack & - & - & 1 & $1,4 \%$ & 1 & $0,7 \%$ \\
\hline $\begin{array}{c}\text { Resistant arterial } \\
\text { hypertension }\end{array}$ & 1 & $1,3 \%$ & 9 & $12,5 \%$ & 10 & $6,7 \%$ \\
\hline
\end{tabular}


As can be seen from the above data, the most frequent type of postoperative hemodynamic disorders were hypertensive reactions, which were observed in 36 out of 150 patients, i.e. in $24 \%$ of cases. This is followed by heart rhythm and conduction disorders (in 24 patients, or $16 \%$ of cases), excessive hypotensive reactions (in 6 patients, or $6 \%$ of cases), postoperative myocardial ischemia (in 2 patients, or $1.3 \%$ of cases), transient ischemic attack (in 10 patients, or $6.7 \%$ of cases), acute myocardial infarction (in 1 patient, or $0.7 \%$ ). There were also resistant arterial hypertension (in 10 cases, or in $6.7 \%$ of patients) and impaired renal function in the form of postoperative decrease in diuresis (13 people, or $8.7 \%$ ).

\section{CONCLUSION}

The study of blood pressure dynamics during ophthalmic surgery showed that hemodynamic parameters in the main group of patients were stable, practically did not differ from the initial values, and in patients of the control group there was an increase in blood pressure SBP $16.3 \%$, heart rate increased by $20.9 \%$, which was absent in patients of the main group.

Against the background of operational stress, the risk of intraoperative and postoperative complications increases. The most effective methods of administration of patients with concomitant arterial hypertension during ophthalmic surgery are: the beginning of sedation in waiting rooms in order to exclude eye contact, psychoemotional stress, the exclusion of drugs that increase systemic blood pressure (atropine, mezaton), the use of mydriacil, which has clear advantages over the traditional use of atropine and NLA.

The obtained data allow us to conclude that effective antihypertensive therapy, exclusion of eye contact in the preoperative period by sedation in waiting rooms using NLA in elderly and senile patients with ophthalmic surgery with hypertension can reduce the pressure load during surgery, and thereby reduce the number of intra and early postoperative complications.

\section{REFERENCES}

1. Amouyel P. The concept of individual cardiovascular risk management / P. Amouyel // Eur. (teart J. Supplements.2000).-P. 2-3.

2. Alieva A.M. Sutochnoe monitorirovanie parametrov funktsionirovaniya serdechno-sosudistoy sistemy u lits starshe 55 let s arterialnoy gipertenziey: Avtoref./Moscow, 2004.

3. Arterial hypertension and circulatory disorders. Timely diagnosis and correction of circulatory disorders allows to increase the effectiveness of treatment AG. / O.D. Ostroumova, V.I. Mamaev, E.I. Pervichko, VV. Baranovskaya // Kardiologiya.-2002.-№ 2.-S. 95-98.

4. Arterial hypertension in patients of advanced age (according to the materials of the XVI1-XX Congress of European Cardiologists I O.D.Ostroumova, V.I- Mamaev, M.V. Nesterova, A.I. Martynov // Cardiology.1999.- №5.-S. 81-82.

5. Branchevskiy S.L., Malyugin B.E. Rasprostranennost narusheniya zreniya vsledstvie catarakty po dannym 
issledovaniya RAAB $v$ Samare / Ophthalmoxirurgiya №3. -2013.

6. Vaydya Romanii. Structural and functional changes of the left ventricle in patients with severe AG with effective antihypertensive therapy: Avtoref. dis ... cand. med. science. Velikiy Novgorod, 2004.- 22 p.

7. Gologorskiy V.A Problems of sedation in intensive care // Bulletin of intensive care. Aktualnue voprosy obshcheyanestezii i sedatsii (Appendix to the journal). -Moscow, -2008, -S.7-13.

8. Gurevich M.A. Arterial hypertension in pojilyx / M.A. Gurevich // M.: Universum Publishing, 2005.-144 p.

9. Eliseev O.M.Est li polza ot provedeniya antihypertenzivnogo lecheniya $v$ vozraste 80 let i starshe? Answer in the results of research HYVET // Terapevt.arx.-2008.-№3.-S.15-22;

10. Karpov Yu. A. Lechenie arterterialnoy gipertonii: novye issledovaniya- novye podkhodb / Yu.A. Karpov // Kardiologiya.-2003.-№ 9.-S. 87-90.

11. Kichin V.V., Kulikov A.S., Lixvantsev V.V. Application of methods of controlled sedation and sedanalgesia in provedeniidlitelnoy IVL patients with acute parenchymatous resection of the lungs // Bulletin of intensive therapy. Moscow: Vitar-M, -2001, №4, -S. 20-25.

12. Matlubov M.M. Kliniko-funktsionalnoe obsledovanie vybora optimalnoy anesteziologicheskoy taktiki pri rodorazreshenii $\mathrm{u}$ patsientok $\mathrm{s}$ ojireniem: Dis.dok.med.nauk. Tashkent, -2018g. -S.50.

13. Nasyrov Sh.N., Sabirov D.M. Arterial hypertension: modern aspects of diagnosis and treatment. -2016. -S.7781.

14. Sidorenko G.I. Psychoemotional tests and their application in cardiology / G.I. Sidorenko, A.V. Frolov, A.L. Vorobev // Cardiology.- 2004.-T.44, № 6.-S. 59-63. 